CLINICAL STUDY

\title{
Autoimmune polyendocrine syndrome type I in Slovakia: relevance of screening patients with autoimmune Addison's disease
}

\author{
Ng'weina F. Magitta ${ }^{1,4,7}$, Mikuláš Pura ${ }^{2}$, Anette S Bøe Wolff ${ }^{3,6}$, Peter Vanuga ${ }^{2}$, Anthony Meager ${ }^{5}$, \\ Per M Knappskog ${ }^{1,7}$ and Eystein S Husebye ${ }^{3,6}$ \\ ${ }^{1}$ Institute for Clinical Medicine, University of Bergen, N-5021 Bergen, Norway, ${ }^{2}$ Department of Endocrinology, National Institute of Endocrinology and \\ Diabetology, 03491 Lubochna, Slovakia, ${ }^{3}$ Section of Endocrinology, Institute of Medicine, University of Bergen, N-5021 Bergen, Norway, ${ }^{4}$ Department of \\ Biochemistry, Muhimbili National Hospital, Muhimbili University of Health and Allied Sciences, PO Box 65001 Dar es Salaam, Tanzania, ${ }^{5}$ The National \\ Institute for Biological Standards and Control, Blanche Lane, South Mimms, Herts EN6 3QG, UK, ${ }^{6}$ Department of Medicine, Haukeland University \\ Hospital, N-5021 Bergen, Norway and ${ }^{7}$ Center for Medical Genetics and Molecular Medicine, Haukeland University Hospital, N-5021 Bergen, Norway \\ (Correspondence should be addressed to E S Husebye; Email: eystein.husebye@helse-bergen.no)
}

\begin{abstract}
Background: Autoimmune polyendocrine syndrome type I (APS I) is a monogenic disease affecting endocrine glands and other organs due to mutations of the autoimmune regulator (AIRE) gene. There is a wide variability in clinical phenotypes in patients with APS I, which makes the diagnosis a challenge. Objective: To screen for APS I among Slovakian patients with sporadic Addison's disease and clinical features that raised the suspicion of APS I.

Methods: All 14 exons and exon-intron boundaries of the AIRE gene were sequenced. In addition, autoantibodies specific for Addison's disease and polyendocrine syndromes were assayed.

Results: Using clinical criteria we identified four patients with APS I in three families. Two patients had a novel missense mutation in exon 2 (c.274C $>$ T, p.R92W) and either the Finnish major mutation (c.769C $>\mathrm{T}$ ) or the common $13 \mathrm{bp}$ deletion (c.967-979del13bp). APS I was diagnosed in a brother of the latter after his death due to an adrenal crisis. A fourth patient had primary adrenal failure and hypoparathyroidism without AIRE mutations or APS-I specific autoantibodies.

Conclusions: Four patients with APS I were found in a Slovakian cohort of Addison patients, although the lack of detectable AIRE mutations and APS I-specific autoantibodies raises uncertainty regarding the pathogenesis in one of the patients. This study demonstrates the merits of screening patients with phenotypic features or autoantibody findings that could indicate APS I, even in adult patients. It is necessary to identify APS I patients in order to provide appropriate treatment and follow-up of the various components of APS I.
\end{abstract}

European Journal of Endocrinology 158 705-709

\section{Introduction}

Autoimmune endocrine diseases tend to associate with each other and with other non-endocrine, organspecific autoimmune disorders. Autoimmune polyendocrine syndrome type I (APS I), also known as autoimmune polyendocrinopathy-candidiasis-ectodermal dystrophy (OMIM no. 240300), is a monogenic polyendocrine autoimmune disorder characterised by primary adrenocortical insufficiency (Addison's disease), primary hypoparathyroidism and chronic mucocutaneous candidiasis $(1,2)$. Two out of these three manifestations are required for the diagnosis, or one component if a sibling already has been diagnosed. Other endocrine components are gonadal failure, diabetes mellitus type 1 , autoimmune thyroid diseases and hypophysitis together with gastrointestinal manifestations such as pernicious anaemia, chronic atrophic gastritis and chronic active hepatitis (2). Finally, ectodermal manifestations are common, i.e. vitiligo, alopecia, keratopathy, enamel hypoplasia and nail dystrophy. The disease typically starts early in childhood with chronic mucocutaneous candidiasis subsequently followed by hypoparathyroidism, Addison's disease and various minor components. However, the severity and mode of presentation shows a wide variability (2-4). An interval varying from years to decades between the occurrences of subsequent manifestations are typically seen and new components can develop throughout life.

Patients with APS I have loss-of-function mutations in the autoimmune regulator (AIRE) gene, localised to chromosome 21q22.3 $(5,6)$. The AIRE protein has structural motifs suggestive of a transcription factor. It is 
largely expressed in the thymic epithelial cells and to some extent in medullary dendritic cells where it plays a major role in the development of central $\mathrm{T}$ cell selftolerance (7). To date about 60 different mutations have been identified throughout the entire coding region of the AIRE gene, the most common being c.769C $>\mathrm{T}$ (Finnish major) and c.967-979del13 (8).

APS I patients have demonstrable circulating antibodies directed against a wide range of self-antigens, most with a restricted tissue distribution corresponding to the organs affected. The majority of patients have antibodies against enzymes involved in the steroid biosynthesis and hepatic metabolism of xenobiotics, i.e. 21-hydroxylase (210H), side-chain cleavage enzyme (SCC) and $17 \alpha$-hydroxylase $(17 \mathrm{OH})$. Other groups are decarboxylases such as aromatic L-amino acid decarboxylase (AADC), glutaminic acid decarboxylase, and pteridine-dependent enzymes such as tryptophan hydroxylase and tyrosine hydroxylase (9). Recently, patients with APS I have been found to have high titres of highly specific neutralising autoantibodies against type I interferons (IFNs), especially IFN- $\alpha$ subtypes and IFN- $\omega(4,10)$.

Since a large variation in phenotype and presentation, even among siblings, has been recognised, the traditional clinical definition does not identify all patients (11). Using careful clinical characterisations, mutational screening of AIRE and assay of specific autoantibodies, we aimed to identify APS I patients in a large cohort of Slovakian patients with primary adrenal failure and polyendocrine syndromes, a population from whom no patients with APS I have been reported previously.

\section{Methods}

\section{Patients' clinical characteristics}

From a cohort of 126 Slovakian patients with Addison's disease, 105 were considered to have autoimmune Addison's disease based on the presence of autoantibodies against 21-hydroxylase $(210 \mathrm{H} ; 63$ patients were positive out of 71 patients analysed, 89\%) and/or presence of another autoimmune disorder, e.g. autoimmune thyroid disease or diabetes mellitus type 1 . The remainder were classified as idiopathic $(n=21)$. Patients with infectious causes of Addison's disease were excluded. The diagnosis of Addison's disease was defined as subnormal serum cortisol together with elevated plasma ACTH concentrations, or failure to reach serum cortisol of $550 \mathrm{nmol} / \mathrm{l}$ at 30 or $60 \mathrm{~min}$ in an i.v. ACTH stimulation test. Mucocutaneous candidiasis was defined as candida infections in the oral mucosa, skin or nails for more than 3 months. Hypoparathyroidism was diagnosed based on the presence of subnormal calcium and supranormal plasma phosphate concentrations, and normal renal function (2). Out of the group of autoimmune and idiopathic Addison's disease patients, 34 were selected for investigations to confirm whether APS I was present based on the following criteria: 1) two of the main components of APS I, 2) Addison's disease diagnosed at $\leq 20$ years of age, 3) positivity for the autoantibodies against AADC, SCC or $17 \mathrm{OH}$ commonly found in APS I patients and 4) the presence of clinical manifestations resembling APS I, i.e. alopecia, vitiligo, autoimmune hepatitis, autoimmune gastritis, keratitis and enamel dysplasia. The mean age at onset of Addison's disease was 30.9 years, and the female-to-male ratio was 2.4:1. The study was approved by the local ethics committee and performed in accordance with the Helsinki Declaration.

\section{DNA extraction}

Genomic DNA was extracted from $10 \mathrm{ml}$ of patients' and healthy blood donors' (controls) peripheral EDTA blood samples using QIAamp blood kit (Qiagen $\mathrm{GmbH}$ ) according to the manufacturer's recommendations. The concentrations of the isolated DNA were determined by spectrophotometry and ascertained to be both quantitatively and qualitatively adequate.

\section{PCR and mutational analysis of the AIRE gene}

DNA was amplified in a $25 \mu \mathrm{l}$ PCR containing about $100 \mathrm{ng}$ of genomic template DNA in $10 \times$ PCR Gold buffer, $1.5 \mathrm{mM} \mathrm{MgCl}_{2}, 0.6 \mu \mathrm{M}$ of each primer, $0.6 \mathrm{mM}$ each dNTP, $1.5 \mathrm{mM}$ betain and 1.0 U Amplitaq Gold DNA polymerase (Applied Biosystems, Foster City, CA, USA). All 14 exons and the exon-intron boundaries of the AIRE gene were amplified. The primers used have been recently described by Wolff et al. (4). Thirty amplification cycles were carried out at PCR thermocycler conditions that included DNA template denaturation at $94{ }^{\circ} \mathrm{C}$ for $20 \mathrm{~s}$, annealing at $58{ }^{\circ} \mathrm{C}$ for $20 \mathrm{~s}$ and extension at $72{ }^{\circ} \mathrm{C}$ for $30 \mathrm{~s}$. Prior to AIRE gene sequencing, $5 \mu \mathrm{l}$ PCR products were purified using an ExoSAP-IT purification kit (USB Corporation, GmbH, Staufen, Germany) according to the manufacturer's protocol. Lastly the products were sequenced using an ABI PRISM 377 automated DNA sequencer and the BigDye Terminator version 1.0 sequencing kit (Applied Biosystems). Both strands of each exon were sequenced and their products compared using SeqScape version 2.5 computer software (Applied Biosystems, Foster City, CA, USA).

\section{Autoantibody assays}

Antibodies against 210H, $17 \mathrm{OH}, \mathrm{SCC}$ and AADC were assayed by immunoprecipitation, based on the antigens synthesised by in vitro transcription and translation as previously described $(9,12)$. Antibodies against type I IFN- $\alpha 2$ and IFN- $\omega$ were performed using antiviral 
interferon neutralisation assays (ANIVA), in which a titre above 40 was considered as a cut-off point for positivity as previously described (10).

\section{Results}

\section{Patients' characteristics and clinical and autoantibody data}

From the cohort of patients defined as suspicious for APS I, we diagnosed four patients with APS I using clinical criteria and sequencing of the coding region of the AIRE gene. Two patients had Addison's disease and hypoparathyroidism, and thus clinical APS I. One of these (patient 1 in Table 1) was diagnosed with Addison's disease at the age of 24 and hypoparathyroidism at the age of 34. Dental enamel hypoplasia became apparent when she was 8 years old, and she also had hypothyroidism. However, we were unable to confirm autoimmunebased hypothyroidism as thyroid autoantibodies were negative (not shown). Moreover, the patient underwent thyroid lobectomy and was on thyroxine replacement therapy at the time of the study. This patient was positive for anti-210H and anti-SCC antibodies and was found to harbour the c.769C $>$ T (p. R257X) mutation in exon 6 and a novel c. $274 \mathrm{C}>\mathrm{T}$ (p. R92W) missense mutation in exon 2 . In addition, she had antibodies against IFN- $\alpha 2$ and IFN- $\omega$ in ANIVA (Table 1) and ELISA (not shown) assays. The patient's brother (patient 2 in Table 1) suffered from adrenal insufficiency (diagnosed at the age of 18), hypothyroidism and primary gonadal failure (onsets unknown). He died in an adrenal crisis at the age of 37. The third patient was diagnosed with Addison's disease and primary gonadal failure at 23 years of age, alopecia areata at the age of 20 and juvenile chronic arthritis at the age of 4 . Serologically, he had high titres of autoantibodies against $210 \mathrm{H}, 17 \mathrm{OH}$, SCC, IFN- $\alpha 2$ and IFN- $\omega$ (Table 1), and the same novel missense mutation (c.274C > T (p. R92W)) in exon 2 as found in patient 1 combined with the common $13 \mathrm{bp}$ deletion c.967979del13 (p. C322fsX372) in exon 8. Although not known to be related, patients 1 and 3 had the same novel AIRE mutation. They originate from neighbouring towns of Slovakia located $20 \mathrm{~km}$ apart. The fourth patient (patient 4 in Table 1 ) also had hypoparathyroidism and Addison's disease, both diagnosed at 28 years of age. Intriguingly, we found none of the typical autoantibodies in her sera, including $210 \mathrm{H}, \mathrm{SCC}, 17 \mathrm{OH}$ and AADC. Assays for IFN- $\alpha 2$ and IFN- $\omega$ antibodies were also negative (Table 1). Finally, sequencing of the coding regions of the AIRE gene failed to detect mutations. As we were unable to confirm specific causes of hypoparathyroidism and adrenal failure, the diagnosis of APS I was made based on clinical criteria.

The c. $274 \mathrm{C}>\mathrm{T}$ mutation found in two of the APS I patients was not detected by sequencing DNA from 80 healthy Slovakian controls. In addition, we found a novel single nucleotide polymorphism in 1 out of the 34 patients located in exon 9 of the AIRE gene, a silent mutation involving a $\mathrm{C}$ to $\mathrm{T}$ transition at position 1065 (c. $1065 \mathrm{C}>\mathrm{T})$. This polymorphism was also found in 1 out of the 80 Slovakian control samples.

\section{Discussion}

From a cohort of 126 patients with autoimmune or idiopathic Addison's disease, we were able to identify 4 patients with APS I. Three could be diagnosed using the clinical criteria, i.e. by the presence of two out of the three main manifestations of chronic mucocutaneous candidiasis, hypoparathyroidism and Addison's disease, or one of these components if a sibling fulfilled the criteria. The fourth patient was identified by mutational analysis of AIRE.

Sera from three patients were available for antibody analysis and revealed typical APS I-autoantibodies in the two individuals with detectable AIRE mutations (patients 1 and 3), while patient 4 with clinical APS I had neither autoantibodies nor detectable mutations in AIRE. Intriguingly, none of the patients had candidiasis

Table 1 Clinical characteristics and results of antibody assays of 4 Slovakian patients with autoimmune polyendocrine syndrome type I (APS I).

\begin{tabular}{|c|c|c|c|c|c|c|c|c|c|c|c|c|}
\hline \multirow{2}{*}{ No. } & \multirow{2}{*}{ Sex } & \multirow{2}{*}{ Age } & \multirow{2}{*}{ On-set ${ }^{a}$} & \multirow{2}{*}{ Manifestations } & \multicolumn{8}{|c|}{ Autoantibody status } \\
\hline & & & & & \multicolumn{2}{|c|}{ Anti-interferon } & \multicolumn{6}{|c|}{ Other } \\
\hline 1 & $\mathrm{~F}$ & 53 & 8 & $\mathrm{AD}, \mathrm{HP}, \mathrm{AIT}, \mathrm{E}$ & 80.000 & 12.000 & + & + & - & - & - & - \\
\hline 2 & $\mathrm{M}$ & $\dagger(37)$ & 18 & $\mathrm{AD}, \mathrm{HG}, \mathrm{AIT}$ & ND & ND & ND & ND & ND & ND & ND & ND \\
\hline 3 & $\mathrm{M}$ & 28 & 23 & $\mathrm{AD}, \mathrm{HG}, \mathrm{AL}, \mathrm{JCA}$ & 512.000 & 200.000 & + & + & + & - & + & + \\
\hline 4 & $\mathrm{~F}$ & 70 & 28 & $\mathrm{AD}, \mathrm{HP}$ & $<40$ & $<40$ & - & - & - & - & - & - \\
\hline
\end{tabular}

AD, Addison's disease; AIT, autoimmune thyroiditis; AL, alopecia; DM, diabetes mellitus type 1; E, dental enamel hypoplasia; HG, hypogonadism; HP, hypoparathyroidism; JCA, juvenile chronic arthritis; IFN- $\alpha 2$, interferon $\alpha 2$; IFN- $\omega$, interferon $\omega$; 21OH, 21-hydroxylase; 17OH, 17 $\alpha$-hydroxylase; SCC, cholesterol side-chain cleaving enzyme; GAD, glutamic acid decarboxylase; IA2, tyrosine phosphatase.

${ }^{\mathrm{a}}$ The age of onset denotes the age at which the first APS I component appear.

$t$, deceased (age); antibodies against $210 \mathrm{H}, \mathrm{SCC}, 17 \mathrm{OH}, \mathrm{AADC}, \mathrm{IA} 2$ and GAD were tested in three of the patients.

+ , presence of autoantibodies.

- , absence of detectable autoantibodies against a given antigen; ND, not determined. 
which is known to be among the earliest and most common manifestations of APS I.

The diagnosis of APS I is not difficult when the patient presents with the typical main manifestations in childhood. However, we and others have shown that the presentation can be highly variable $(1,4,11,13)$, giving rise to a considerable overlap in clinical presentation between APS I and the more common polyendocrinopathies. Thus, the patient with Addison's disease and gonadal failure would have been classified as APS IV on clinical criteria (14), but turned out to have APS I when assay of interferon antibodies and mutational analysis of the AIRE gene were performed. It is important to identify APS I patients at an early stage. They can develop new and potentially fatal manifestations throughout life, and these patients need a much closer follow-up than those with the more common forms of Addison's disease and polyendocrinopathy (APS II and IV). Intriguingly, three out of the four Slovakian patients identified in this study had their first APS I disease manifestation diagnosed between the age of 18 and 28 years. This is late compared with the typical presentation in early childhood $(1,2)$, and underpins the fact that even patients with debut in early adult life may have APS I. Moreover, none of the Slovakian patients described here had mucocutaneous candidiasis, one of the common and early manifestations of this disease in most populations. One exception is Iranian Jews with APS I, who typically are homozygous for the c. $254 \mathrm{~A}>\mathrm{G}$ (p.Y85C) mutation in the AIRE gene $(15,16)$, who display a frequency of candidiasis of about $20 \%$ compared with close to $100 \%$ in Norway and Finland (3). Interestingly, the Iranian Jews missense mutation p.Y85C is located close to the novel Slovakian mutation p.R92W reported here. Finally, the fact that we identified no children in this study is probably due to a selection bias since we studied a cohort of Addison patients.

Two previous studies revealed extremely low prevalence of the two predominant AIRE mutations in patients with sporadic Addison's disease, other isolated autoimmune disorders and the general population $(17,18)$. Meyer and colleagues found one p. R257X heterozygous mutation among 175 patients with Hashimoto's thyroiditis and none with c.967979 del13 deletion in a subgroup of 91 patients with isolated Addison's disease (17). Another study found one patient with autoimmune Addison's disease out of 90 to be heterozygous for the common 13 bp deletion (18). However, these studies only screened for the two major mutations (c.769C $>\mathrm{T}$ and c.967-979del13), whereas we sequenced the whole gene. Thus, the possibility of other undetected mutations in other regions of AIRE gene could not be ruled out.

In the papers published so far, all APS I patients display one or more antibodies against type 1 interferons $(4,10)$. In this study, one patient was negative but we were also unable to detect mutations in the AIRE gene, which underpins the specificity of the interferon antibodies in diagnosing APS I. Even if this individual fulfilled the clinical criteria, our finding may also indicate that the polyendocrine failure in this patient has another aetiology.

In conclusion, this study reports the first Slovakian APS I patients. Based on our findings we argue for an active screening for APS I in patients developing Addison's disease before 30 years of age and with polyendocrine failure. Assay of APS I-specific autoantibodies, particularly the antibodies against interferons, is a fast and convenient way of identifying suspected APS I patients, but the diagnosis should be secured by mutational analyses of the AIRE gene in those who are positive. In some populations, e.g. among Finns, Iranian Jews and Sardinians, it is sufficient to start with an analysis of the major mutations whereas in other populations full sequencing of AIRE should be performed.

\section{Acknowledgements}

We are indebted to all colleagues in Endocrinology and Diabetology Departments, National Institute of Endocrinology and Diabetology, Lubochna, for comprehension and referring their patients. The excellent technical assistance of nurses from in-patient and out-patient basis of National Institute of Endocrinology and Diabetology, Lubochna, for sample collection is gratefully acknowledged. Special thanks to Mária Petríková, Miriam Balejová and Katarína Krónerová for helping in recruiting patients and managing the blood-taking procedures. At Haukeland Hospital, Kristin Moen and Paal Henning Borge are greatly thanked for assisting in performing autoantibody analyses and AIRE sequencing respectively. The study was supported by grants from Helse Vest and the EU 6th Framework programme (EurAPS). Magitta and Pura contributed equally to this work.

\section{References}

1 Perheentupa J. Autoimmune polyendocrinopathy-candidiasisectodermal dystrophy. Journal Clinical Endocrinology and Metabolism $2006912843-2850$.

2 Ahonen P, Myllärniemi S, Sipilä I \& Perheentupa J. Clinical variation of autoimmune polyendocrinopathy-candidiasisectodermal dystrophy (APECED) in a series of 68 patients. New England Journal of Medicine 1990322 1829-1836.

3 Myhre AG, Halonen M, Eskelin P, Ekwall O, Hedstrand H, Rorsman F, Kämpe O \& Husebye ES. Autoimmune polyendocrine syndrome type 1 (APS I) in Norway. Clinical Endocrinology 2001 $54211-217$

4 Wolff AS, Erichsen MM, Meager A, Magitta NF, Myhre AG, Bollerslev J, Fougner KJ, Lima K, Knappskog PM \& Husebye ES. Autoimmune polyendocrine syndrome type 1 in Norway: phenotypic variation, autoantibodies, and novel mutations in the autoimmune regulator gene. Journal Clinical Endocrinology and Metabolism 200792 595-603. 
5 The Finnish-German APECED Consortium. An autoimmune disease, APECED, caused by mutations in a novel gene featuring two PHDtype zinc-finger domains. Nature Genetics 199717 399-403.

6 Nagamine K, Peterson P, Scott HS, Kudoh J, Minoshima S, Heino M, Krohn KJ, Lalioti MD, Mullis PE, Antonarakis SE, Kawasaki K, Asakawa S, Ito F \& Shimizu N. Positional cloning of the APECED gene. Nature Genetics 199717 393-398.

7 Anderson MS, Venanzi ES, Klein L, Chen Z, Berzins SP, Turley SJ, von Boehmer H, Bronson R, Dierich A, Benoist C \& Mathis D. Projection of an immunological self shadow within the thymus by the aire protein. Science 2002298 1395-1401.

8 Pitkänen J \& Peterson P. Autoimmune regulator: from loss of function to autoimmunity. Genes and Immunity 20034 12-21.

9 Söderbergh A, Myhre AG, Ekwall O, Gebre-Medhin G, Hedstrand H, Landgren E, Miettinen A, Eskelin P, Halonen M, Tuomi T, Gustafsson J, Husebye ES, Perheentupa J, Gylling M, Manns MP, Rorsman F, Kämpe O \& Nilsson T. Prevalence and clinical associations of 10 defined autoantibodies in autoimmune polyendocrine syndrome type I. Journal Clinical Endocrinology and Metabolism $200489557-562$.

10 Meager A, Visvalingam K, Peterson P, Moll K, Murumagi A, Krohn K, Eskelin P, Perheentupa J, Husebye E, Kadota Y \& Willcox N. Anti-interferon autoantibodies in autoimmune polyendocrinopathy syndrome type 1. PLoS Medicine 20063 e289.

11 Bøe AS, Knappskog PM, Myhre AG, Sørheim JI \& Husebye ES. Mutational analysis of the autoimmune regulator (AIRE) gene in sporadic autoimmune Addison's disease can reveal patients with unidentified autoimmune polyendocrine syndrome type I. European Journal of Endocrinology 2002146 519-522.

12 Ekwall O, Hedstrand H, Grimelius L, Haavik J, Perheentupa J, Gustafsson J, Husebye E, Kämpe O \& Rorsman F. Identification of tryptophan hydroxylase as an intestinal autoantigen. Lancet 1998 352 279-283.
13 Buzi F, Badolato R, Mazza C, Giliani S, Notarangelo LD, Radetti G \& Plebani A. Autoimmune polyendocrinopathycandidiasis-ectodermal dystrophy syndrome: time to review diagnostic criteria? Journal Clinical Endocrinology and Metabolism 200388 3146-3148.

14 Arlt W \& Allolio B. Adrenal insufficiency. Lancet 2003361 1881-1893.

15 Björses P, Halonen M, Palvimo JJ, Kolmer M, Aaltonen J, Ellonen P, Perheentupa J, Ulmanen I \& Peltonen L. Mutations in the AIRE gene: effects on subcellular location and transactivation function of the autoimmune polyendocrinopathy- candidiasis-ectodermal dystrophy protein. American Journal of Human Genetics $2000 \mathbf{6 6}$ 378-392.

16 Zlotogora J \& Shapiro MS. Polyglandular autoimmune syndrome type I among Iranian Jews. Journal of Medical Genetics 199229 824-826.

17 Meyer G, Donner H, Herwig J, Bohles H, Usadel KH \& Badenhoop K. Screening for an AIRE-1 mutation in patients with Addison's disease, type 1 diabetes, Graves' disease and Hashimoto's thyroiditis as well as in APECED syndrome. Clinical Endocrinology 200154 335-338.

18 Vaidya B, Imrie H, Geatch DR, Perros P, Ball SG, Baylis PH, Carr D, Hurel SJ, James RA, Kelly WF, Kemp EH, Young ET, Weetman AP, Kendall-Taylor P \& Pearce SH. Association analysis of the cytotoxic T lymphocyte antigen-4 (CTLA-4) and autoimmune regulator-1 (AIRE-1) genes in sporadic autoimmune Addison's disease. Journal Clinical Endocrinology and Metabolism 200085 688-691.

Received 6 February 2008

Accepted 7 February 2008 